\title{
RECURSOS HÍdRICOS E SAÚdE PÚBLICA
}

\author{
WATER LAWAND PUBLIC HEALTH
}

Maria Luiza Machado Granziera(*)

\section{RESUMO}

É indiscutível o entendimento da água como fator de saúde pública. De todos os temas que daí podem ser retirados e desenvolvidos, há dois tipos de utilização da água que concerne diretamente à saúde das pessoas: o consumo humano e o lançamento de efluentes nos rios.

A água, para não prejudicar a saúde da população, deve ser consumida em padrões mínimos de potabilidade, definidos pela legislação. É dever do Poder Público garantir a saúde $e$, dentre as inúmeras atividades voltadas $a$ isso, deve fornecer água em condições de potabilidade.

Já as águas servidas não devem ser lançadas nos corpos hídricos sem tratamento prévio, de modo a não causar poluição nem contaminar as derivações rio abaixo, muitas delas destinadas ao abastecimento público.

A legislação brasileira, para atender às novas demandas relativas à proteção desse precioso recurso, modernizou-se e as novas regras em vigor, consubstanciadas em políticas de recursos hídricos, em âmbito nacional e estadual, organizam a necessidade de proteção da água. Todavia, é necessário que, além da regulamentação dessas normas, muitas medidas de implementação sejam adotadas, no sentido de propiciar a efetividade das mesmas.

\section{Palavras-chave}

Água, Recursos Hídricos, Lei, Saneamento, Saúde pública.

(") Advogada, mestra e doutora em Direito e autora do livro Direito de Águas, publicado pela Editora Atlas. 


\section{ABSTRACT}

The relation of water as a source of public heath is unquestionable. From the development of this relation, there are two types of water usage that is directly concerned to people's health (public health): water supply and sewage release in rivers.

In order for water not to harm public health, it should be consumed (supplied) at a minimum standard of potability defined by the legislation. It is the government's duty to guarantee health which, among inumerous related activities, involves supplying potable water.

As far as sewage is concerned, it should not be released into bodies of water without any previous treatment, so that it does not cause pollution ${ }_{1}$ nor does it contaminate any of the river's sources - many of which are destined to public supply.

The Brazilian legislation has been updated, in order to comply to the new demands of this precious resource's protection, and these new rules (laws) in force natiowide and statewide, within water resource policies, have organized the need of water protection. However, it is necessary to adopt, beyond these new laws, (many) implementation measures so that these will be effective.

\section{Keywords}

Water policies, Legislation, Public health, Water usage.

\section{INTRODUÇÃO}

Cada dólar aplicado no saneamento básico representa a economia de 4 a 5 dólares no setor de saúde, pelos próximos dez anos. Esse dado, divulgado pelo Ministério da Saúde, vem demonstrar a importância do saneamento em relação à saúde pública. Mais que isso, é um indicador para os investimentos públicos de forma racional, em tempos em que o dinheiro se encontra escasso no País.

Fala-se muito em proteçẳo ambiental, mas é preciso levar em conta que, dentre os inúmeros condicionantes dessa proteção, a questão da saúde possui um peso considerável. A própria Lei n. 6.938, de 31 de agosto de 1981, que instituiu a Política Nacional do Meio Ambiente, em seu art. $3^{\circ}$, inciso III, define como poluição a degradação da qualidade ambiental resultante de atividades, dentre outras condições, que, direta ou indiretamente, "prejudiquem a saúde, a segurança e o bem-estar da população". 
A água é fundamental para a sobrevivência do homem, mas pode também constituir fator de moléstias provocadas pelos vetores que se abrigam na água, se não se tomarem as necessárias medidas de proteção aos recursos hídricos - sejam os mananciais para o abastecimento público, sejam os corpos hídricos receptores dos esgotos.

Daí a necessidade de haver uma convergência nas ações do governo e também da sociedade, de modo que se garanta a proteção da água, que também é recurso natural, visando, entre outros fatores, à saúde da população.

Basicamente, a saúde pública é afetada pela água no que toca ao consumo humano, em que os padrões de potabilidade devem ser obrigatoriamente observados na poluição hídrica, essa causada seja por rejeitos industriais fora dos padrões legalmente fixados, seja pelo lançamento de esgotos domésticos sem o devido tratamento.

\section{PRINCÍPIOS RELACIONADOS COM SAÚdE E MEIO AMBIENTE}

\subsection{O direito humano a um meio ambiente saudável}

Dentre as declarações internacionais que consagram, no plano internacional, o reconhecimento de um direito humano ao meio ambiente, ou a importância fundamental deste ao homem, se destaca a Declaração de Estocolmo, de 1972, cujo princípio n. 1 estabelece que "o homem tem o direito fundamental à liberdade, à igualdade e ao desfrute de condições de vida adequadas, em um meio ambiente de qualidade tal que permita levar uma vida digna, gozar de bem-estar e é portador solene de obrigação de proteger e melhorar o meio ambiente, para as gerações presentes e futuras".(1) Condições de vida adequadas não podem prescindir da saúde, que indiretamente está contida nesse princípio.

A Carta Africana de Direitos Humanos e dos Povos, declarada em Nairóbi, em 28 de junho de 1981, proclama, em seu artigo 24, que "todos os povos têm direito a um meio ambiente satisfatório e global, propício ao seu desenvolvimento". (2) Também aqui está implícita a condição de saúde, pois não há desenvolvimento em um meio insalubre.

Michel Prieur pondera que o direito ao meio ambiente, como direito humano, enseja alguma dificuldade em sua formulação concreta, pois a proteção ambiental concerne não só ao homem, mas a todos os seres

(1) Veiga da CUNHA. A Gestão da Água. Lisboa: Fundação Calouste Gulbenkian, 1980, p. 532.

(2) Michel PRIEUR. Droit de L'Environnement. Paris: Dalloz, 1996, p. 59. 
vivos e à biosfera. Mais que um direito humano no sentido estrito, deve tratar-se de um direito da espécie que protege tanto o homem como o meio em que ele vive. ${ }^{(3)} \mathrm{De}$ acordo com esse posicionamento, o homem faz parte do meio ambiente, integrando a natureza.

Nesse sentido, a Conferência das Nações Unidas sobre Meio Ambiente e Desenvolvimento parece ter colocado a questão com maior propriedade, fixando, em seu princípio n. 1, que "os seres humanos estão no centro das preocupações com o desenvolvimento sustentável. Têm direito a uma vida saudável e produtiva, em harmonia com a natureza".

No campo normativo brasileiro, 0 art. 225 da Constituição Federal dispõe, em seu caput, que "todos têm direito ao meio ambiente ecologicamente equilibrado, bem de uso comum do povo e essencial à sadia qualidade de vida, impondo-se ao Poder Público e à coletividade o dever de defendê-lo e preservá-lo para as presentes e futuras gerações".

Ficou assim transportado para a ordem constitucional brasileira o entendimento de que o meio ambiente equilibrado - e essa palavra possui uma conotação bastante abrangente, incluindo a saúde - constitui direito de todos e que se trata de bem de uso comum do povo. Além disso, sua defesa e proteção, por conseguinte, compete ao Poder Público e à coletividade, ou seja, a todos cabe o direito de uso, assim como a responsabilidade pela proteção do meio ambiente.

Destaca-se ainda a noção de "sadia qualidade de vida". A condição imposta é que a proteção ambiental é essencial a fatores de qualidade de vida, destacando-se aí a própria saúde.

A Conferência de Paris, realizada em 1998, estabelece que "os recursos hídricos são essenciais para a satisfação das atividades humanas, tanto as básicas como aquelas vinculadas à saúde, à produção de energia, alimentos e assim como à preservação dos ecossistemas e do desenvolvimento econômico em todas as suas fases: social, política, etc.". Além disso, "é imprescindível que os países ribeirinhos compartilhem uma visão comum com miras ao aproveitamento, gestão e proteção eficazes das águas de curso sucessivo, de tipo doce e de natureza fronteiriça". ${ }^{(4)}$

\subsection{Desenvolvimento sustentável}

A Conferência de Estocolmo, ${ }^{(5)}$ sobre meio ambiente, realizada em 1972, estabeleceu em seus princípios o planejamento racional e a adoção,

\footnotetext{
(3) Idem, ibidem, p. 65.

(4) Águas - Aspectos Juridicos e Ambientais. Coord. Vladimir Passos de Freitas. Curitiba: Juruá, 2000, Anexo III, p. 250.

(5) Veiga da CUNHA, A Gestão da Água, cit., p. 532.
} 
pelos Estados, de uma concepção integrada e coordenada do planejamento de seu desenvolvimento, para compatibilizar a necessidade de proteger e de melhorar o ambiente, no interesse de sua população. $O$ princípio $n .13$ preconizou que "a fim de lograr um ordenamento mais racional dos recursos e, assim, melhorar as condições ambientais, os Estados deveriam adotar um enfoque integrado e coordenado da planificação de seu desenvolvimento, de modo que fique assegurada a compatibilidade do desenvolvimento com a necessidade de proteger e melhorar o meio ambiente humano, em benefício da população". ${ }^{(6)}$

"Até então, no Brasil, assim como em todo o Terceiro Mundo, o desenvolvimento econômico constituia a grande promessa para tirar o País da situação de subdesenvolvimento e 'alçá-lo' à categoria de Estado 'em desenvolvimento"'. Tinha, portanto, prioridade sobre qualquer outra preocupação que pudesse vir à baila, inclusive o meio ambiente e, conseqüentemente, a saúde pública. ${ }^{(7)}$

A Conferência da ONU, de 1972, deflagrou o alerta, pois mostrou ao mundo os efeitos do desenvolvimento e da industrialização, sem um planejamento e uma cautela especial, na preservação dos recursos naturais. ${ }^{(8)}$

Já posteriormente, o direcionamento de ações voltadas ao progresso das relações econômicas e as reflexões sobre os efeitos de tais atividades levou os estudiosos ao conceito do desenvolvimento sustentável, em que se permite e se encoraja o desenvolvimento, desde que adequado às normas de proteção ambiental.

No que se refere ao campo conceitual da expressão "desenvolvimento sustentável", a Comissão Mundial sobre Meio Ambiente e Desenvolvimento, criada pela Organização das Nações Unidas com o objetivo de propor novas medidas tendentes a combater a degradação ambiental e a meIhorar as condições de vida das populações carentes, da qual resultou 0 "Relatório Bruntland"(9), convencionou denominar desenvolvimento sustentável da seguinte forma:

"Desenvolvimento sustentável é o desenvolvimento capaz de garantir as necessidades do presente sem comprometer a capacidade das gerações futuras de atenderem às suas necessidades".(10)

(6) Geraldo Eulálio Nascimento e SILVA, Direito Ambiental Internacional. Rio de Janeiro: Thex Editora, Biblioteca Estácio de Sá, 1995, p. 164.

(7) Maria Luiza Machado GRANZIERA, "Processo de Licenciamento Ambiental", in Processo Administrativo: Aspectos Atuais. Coord. Odete Medauar. São Paulo: Cultural Paulista, 1998, p. 429.

(8) Idem, ibidem.

(9) O Relatório Bruntland denominou-se "Nosso Futuro Comum".

(10) O Geraldo Eulálio Nascimento e SILVA, Direito Ambiental Internacional, Rio de Janeiro: Thex Editora, Biblioteca Estácio de Sá, 1995, p. 48. 
Evidentemente, a questão da saúde pública está implícita nesse conceito, à medida que não haveria sentido excluir a proteção da saúde, nas considerações sobre as gerações futuras.

Na Declaração do Rio de Janeiro sobre Meio Ambiente e Desenvolvimento, de 1992, a expressão "desenvolvimento sustentável" permeia todos os documentos correlatos, principalmente a Agenda 21. Repete-se várias vezes a expressão, o que enfatiza a idéia de que o desenvolvimento econômico deve, necessariamente, incluir a proteção do meio ambiente em todas as suas ações e atividades, para garantir a permanência do equilíbrio ecológico e da qualidade da vida humana, inclusive para as futuras gerações. Não se pode pensar em qualidade de vida humana que não preveja a proteção à saúde.

Para assegurar o cumprimento desse princípio, deve haver um mecanismo institucional de controle das atividades, de modo que se possa aferir se as normas previstas na legislação em vigor, concernentes à proteção do meio ambiente, estão sendo corretamente observadas pelos empreendedores. Essa competência se refere às leis e ao exercício do poder de polícia, no que tange ao estabelecimento de regulamentos, normas e padrões ambientais, a serem observados pelos empreendedores e pela Administração Pública, na fiscalização e aplicação de penalidades, pois não basta que inicialmente se comprove a sustentabilidade de um empreendimento, é preciso que a mesma perdure ao longo de toda a atividade.

O desenvolvimento sustentável é um princípio atinente a toda política ambiental, pois possui interfaces com a outorga do direito de uso da água, o licenciamento ambiental, os usos múltiplos, a noção de bacia hidrográfica como unidade de planejamento e gerenciamento.

No que se refere aos recursos hídricos, nos termos da Convenção de Paris, de 1998, "é indispensável incentivar o conhecimento e a compreensão dos recursos hídricos em todos os níveis, a fim de melhorar o seu aproveitamento, gestão e proteção, promovendo sua utilização mais eficaz, eqüitativa e sustentável".(11)

Como se pode notar, a noção de desenvolvimento sustentável não disassocia a proteção ambiental da saúde, pois, ao ter como foco as futuras gerações, fica implícita a manutenção da saúde para que essas possam existir e exercer as atividades necessárias à sua sobrevivência e ao seu desenvolvimento.

(11) Aguas - Aspectos Jurídicos e Ambientais. Coord. Vladimir Passos de Freitas, cit., Anexo III, p. 250. 


\subsection{Princípio da prevenção}

"A prevenção consiste em impedir a superveniência de danos ao meio ambiente por meio de medidas apropriadas, ditas preventivas, antes da elaboração de um plano ou da realização de uma obra ou atividade."(12)

Constata-se que há correspondência entre os vocábulos "prevenção" e "precaução". Todavia, a doutrina optou por distinguir o sentido desses termos, constituindo o princípio da precaução um estágio além da prevenção, à medida que o primeiro tende a não realização do empreendimento, se houver risco de dano irreversível, e o segundo busca, ao menos em um primeiro momento, a compatibilização entre a atividade e a proteção ambiental. Pode ser mantida a distinção por razões metodológicas.

Havendo uma análise prévia dos impactos que um determinado empreendimento pode causar ao meio ambiente, é possível, por meio da adoção de medidas compensatórias e mitigadoras, e mesmo da alteração do projeto em análise, se for o caso, assegurar a sua realização, garantindo-se os benefícios econômicos do mesmo decorrentes, sem causar dano ao meio ambiente e à saúde.

O reflexo mais evidente do princípio da prevenção, no campo normativo brasileiro, é o Estudo Prévio de Impacto Ambiental (EPIA). O EPIA foi fixado na Lei n. 6.938/81 como um dos instrumentos da Política Nacional do Meio Ambiente e posteriormente alçado à categoria de norma constitucional, no art. 225, inciso IV, da CF, que dispõe sobre "exigir, na forma da lei, para instalação de obra ou atividade potencialmente causadora de significativa degradação do meio ambiente, estudo prévio de impacto ambiental, a que se dará publicidade".

Segundo Paulo de Bessa Antunes, "a importância fundamental dos Estudos de Impacto Ambiental reside no fato de que, pela sua correta realização, é possível se antecipar conseqüências negativas e positivas e medir as alternativas apresentadas com vistas a uma opção a ser decidida pela sociedade". ${ }^{13)}$ Ou seja, assegurar o desenvolvimento, prevenindo danos futuros, inclusive à saúde.

\subsection{Princípio da precaução}

O princípio da precaução apresenta-se como o cerne do direito ambiental. São seus elementos que compõem exatamente o que se chama de proteção ao meio ambiente, para as atuais e futuras gerações. Segundo Cristiane Derani, "esse princípio indica uma atuação 'racional' para com os

(12) Michel PRIEUR, op. cit., p. 70.

(13) Direito Ambiental. Rio de Janeiro: Lumen Juris, 1996, p. 14. 
bens ambientais, com a mais cuidadosa apreensão possível dos recursos naturais, $[. .$.$] que vai além das simples medidas para afastar o perigo.$ Na verdade, é uma 'precaução contra o risco', que objetiva prevenir já uma suspeição de perigo ou garantir uma suficiente margem de segurança da linha do perigo". ${ }^{(14)}$ Tais considerações podem ser interpretadas com o foco na saúde.

Com o intuito de evitar desagradáveis surpresas em matéria de degradação ambiental e de risco de dano à saúde, vem o princípio da precaução determinar que, na dúvida, é melhor tomar providências drásticas, no sentido de evitar danos futuros, por ignorância das conseqüências que certos empreendimentos e substâncias podem causar.

Ou seja, como um passo posterior ao desenvolvimento sustentável, e ao princípio da prevenção, o princípio da precaução pende para a "não ação", ao "não desenvolvimento", toda vez que se entender, no caso concreto, que essa ação - ou esse desenvolvimento - pode causar danos irreversíveis ao ambiente e à saúde.

De acordo com Michel Prieur, "em face da incerteza ou da controvérsia científica atual, é melhor tomar medidas de proteção severas do que nada fazer. É, em realidade, implementar o direito ao meio ambiente às futuras gerações".(15)

Estabelece o princípio n. 15 da Declaração do Rio de Janeiro que "para proteger o meio ambiente, o princípio da precaução deve ser amplamente observado pelos Estados, de acordo com suas capacidades. Em caso de risco de danos graves ou irreversíveis, a ausência de certeza científica absoluta não deve servir de pretexto para procrastinar a adoção de medidas visando a prevenir a degradação do meio ambiente".

Sobre o assunto, Paulo Affonso Leme Machado manifesta-se ainda no sentido de que "não é preciso que se tenha prova científica absoluta de que ocorrerá dano ambiental, bastando o risco de que o dano seja irreversível para que não se deixem para depois as medidas efetivas de proteção ao ambiente. Existindo dúvida sobre a possibilidade futura de dano ao homem e ao meio ambiente, a solução deve ser favorável ao ambiente e não ao lucro imediato - por mais atraente que seja para as gerações presentes". ${ }^{(16)}$

$\mathrm{Na}$ verdade, o risco existe em todas as atividades. O que varia é a probabilidade de ocorrência do dano. Havendo maior probabilidade, e de

(14) Direito Ambiental Económico. São Paulo: Max Limonad, 1997, p. 165.

(15) Op. cit., p. 144.

(16) Direito Ambiental Brasileiro. 6ª ed. São Paulo: Malheiros, 1996, p. 507. 
acordo com a natureza do dano em potencial, a atividade não deve ser licenciada.

\section{OS RECURSOS HÍDRICOS, O MEIO AMBIENTE E A SAÚDE NA CONSTITUIÇÃO FEDERAL}

A relação do meio ambiente e dos recursos hídricos com a saúde fica claramente demonstrada na Constituição Federal. Em seu art. 225, é assegurado a todos o "direito ao meio ambiente ecologicamente equilibrado, bem de uso comum do povo e essencial à sadia qualidade de vida...".

Para assegurar a efetividade desse direito, 0 art. $225, \S 11^{\circ}$, inciso V, incumbe ao Poder Público "controlar a produção, a comercialização e o emprego de técnicas, métodos e substâncias que comportem risco para a vida, a qualidade de vida e o meio ambiente". O efetivo equilíbrio do meio ambiente, dessa forma, é requisito para a manutenção da saúde.

O art. 200 da Constituição, que trata do Sistema Único de Saúde (SUS), fixa-lhe competência para "participar da formulação da política e da execução das ações de saneamento básico" (inciso IV) e "fiscalizar e inspecionar alimentos, compreendido o controle de seu teor nutricional, bem como bebidas e águas para consumo humano" (inciso VI). Em ambos os incisos, as atribuições do Sistema Único de Saúde reportam-se a questões ambientais. Cabe destacar ainda o contido no inciso VIII do art. 200 do mesmo diploma, que estabelece maior nitidez na relação em tela, pois dá competência ao SUS para "colaborar na proteção do meio ambiente, nele compreendido o do trabalho".

\section{A LEI N. 8.080, DE 19.9.1990}

$\mathrm{O}$ art. $3^{\circ}$ da Lei n. 8.080/90 estabelece, como fatores determinantes e condicionantes da saúde, "a alimentação, a moradia, o saneamento básico, o meio ambiente, o trabalho, a renda, a educação, o transporte, o lazer e os bens e serviços essenciais". Dispõe ainda o citado dispositivo legal que "os níveis de saúde da população expressam a organização social econômica do País". Conforme seu parágrafo único, "dizem respeito à saúde as ações que por força do disposto no artigo anterior, se destinam a garantir às pessoas e à coletividade condições de bem-estar físico, mental e social". Clara fica a importância de se considerar o meio ambiente quando se trata de saúde; ele a determina e a condiciona.

Conforme 0 art. $6^{\circ}$, inclui-se no campo de atuação do Sistema Único de Saúde (SUS) a execução das ações de vigilância sanitária, sendo esta 
definida, no inciso XI, $\S 1^{\circ}$, como "um conjunto de ações capaz de eliminar, diminuir ou prevenir riscos à saúde e de intervir nos problemas sanitários decorrentes do meio ambiente, da produção e circulação de bens e da prestação de serviços de interesse da saúde". Logo, a vigilância sanitária é uma função que se relaciona a problemas provenientes, inclusive, do meio ambiente.

Também faz parte da atuação do SUS, conforme o inciso IX, do art. 60, "a participação no controle e na fiscalização da produção, transporte, guarda e utilização de substâncias e produtos psicoativos, tóxicos e radioativos".

No art. $7^{\circ}$, inciso $X$, destaca-se um princípio que deve ser observado pelos agentes que integram o SUS: "integração em nivel executivo das ações de saúde, meio ambiente e saneamento básico". A integração da saúde com o meio ambiente manifesta-se como vontade do legislador.

O art. 13 dispõe que "a articulação das políticas e programas, a cargo das comissões intersetoriais, abrangerá...", dentre outras, o saneamento e o meio ambiente. Mais uma vez nota-se a inclusão do meio ambiente nas atividades do SUS. Isso também fica claro no art. 16, inciso II, segundo o qual compete à direção nacional do SUS, "participar na formulação e na implementação das políticas: a) de controle das agressões ao meio ambiente; b) de saneamento básico". O inciso IV fixa a competência para "participar da definição de normas e mecanismos de controle, com órgãos afins, de agravo sobre o meio ambiente ou dele decorrentes, que tenham repercussão na saúde humana".

Como se vê, é necessária a compatibilização das ações atinentes tanto à manutenção da saúde como à proteção do meio ambiente, como forma de assegurar o desenvolvimento sustentável, ou seja, a manutenção das atividades atualmente exercidas, para as futuras gerações.

\section{A ÁGUA COMO FATOR CONDICIONANTE DA SAÚDE}

\subsection{Consumo humano e saneamento básico}

O consumo humano constitui o uso prioritário da água, pois relaciona-se diretamente como o direito à vida. $O$ abastecimento de água potável insere-se no saneamento básico, que deve ser entendido aqui como os serviços de água e esgoto, ou seja, "a solução dos problemas relacionados estritamente com o abastecimento de água e a disposição dos esgotos de uma comunidade".(17)

(17) Vocabulário Básico de Meio Ambiente. Coord. lara Verocai Dias Moreira. Rio de Janeiro: Petrobrás, 1990, p. 182. 
Trata-se do mais importante uso da água, principalmente pela prioridade que se dá ao abastecimento de água potável às populações, garantia da própria vida, além de sua interface com as questões ambientais e de saúde, provocadas pelo lançamento de esgotos in natura nos corpos hídricos, problema que assola grande parte dos municípios do País.

O abastecimento de água potável, por meio de canalização, é, hoje, um indicador de desenvolvimento de um país, principalmente pela estreita relação do abastecimento com a própria saúde pública.

Nos grandes centros urbanos, vultosos são os sistemas de captação, tratamento, adução e distribuição de água, assim como os de coleta, tratamento dos esgotos e disposição final dos lodos provenientes desse tratamento.

Esses sistemas, cuja finalidade alcança a proteção da saúde pública, podem, se não estiverem implantados e organizados, causar sérios impactos na qualidade e na quantidade dos recursos hídricos. É dever do Poder Público garantir o abastecimento de água potável à população, que pode ser obtido dos rios, reservatórios ou dos aqüíferos. A água que se deriva dos mananciais, para o abastecimento público, deve possuir condições tais que, mediante tratamento, em vários níveis, possa ser fornecida à população nos padrões legalmente estabelecidos de potabilidade, sem qualquer risco de contaminação.

É digno de nota que o fator "captação da água" se encontra estreitamente ligado à idéia do "lançamento das águas servidas". Parte da água captada é devolvida após o uso, o que implica que a água servida deve se submeter a tratamento antes do lançamento, para que não prejudique a qualidade do corpo receptor $e$, conseqüentemente, não cause dano à saúde da comunidade.

Em rios que banham várias cidades, muitas vezes o ponto de captação de águas para o abastecimento de uma cidade localiza-se a jusante (rio abaixo) do ponto de despejo da cidade, que se situa a montante (rio acima).

Se as águas servidas não são submetidas a tratamento antes de seu despejo, pode ficar seriamente comprometido o abastecimento da cidade que se encontra a jusante, pelo despejo dos esgotos provenientes daquela localizada rio acima, havendo risco de sérios danos à saúde.

\subsection{Classificação e enquadramento dos corpos hídricos em classes,} segundo os usos preponderantes

Há na legislação brasileira regras sobre a qualidade das águas, definindo-se os usos preponderantes mais adequados em relação à qualida- 
de. Conforme pondera Despax, "deve ser considerado que o objeto de uma política de prevenção não pode ser a proibição de qualquer poluição, mas apenas a prevenção de um certo grau, para manter a poluição em níveis razoáveis". ${ }^{(18)}$ Ou seja, não se pretende que as águas retornem à pureza anterior ao aparecimento do homem, mas que os aspectos de quantidade e qualidade sejam mantidos para as atuais e futuras gerações.

Daí a introdução da classificação e do enquadramento dos corpos hídricos no ordenamento jurídico.

Em matéria de águas, classificar significa estabelecer níveis de qualidade para as águas - doces, salobras e salinas -, em face dos quais se priorizam determinados tipos de uso, mais ou menos exigentes.

A classificação das águas é regida pela Resolução CONAMA 20, de 18.6.1986 que, em seus "consideranda", fornece importantes subsídios para o entendimento do conceito. Nos termos do art. $2^{\circ}$ da citada Resolução e do art. ${ }^{9}$, inciso II, da Resolução do Conselho Nacional de Recursos Hídricos $\mathrm{CNRH} 12$, de 19.7.2000, classificação consiste na "qualificação das águas doces, salobras e salinas com base nos usos preponderantes (sistema de classes de qualidade)".

A classificação dos corpos hídricos refere-se às águas doces, salinas e salobras. O critério de distinção entre essas espécies do gênero água é na quantidade de sal dissolvido. De acordo com a CONAMA 20, o art. $2^{\circ}$, alínea $e, f$ e $g$ a salinidade das águas doces é igual ou inferior a $0,50 \% 0$, das salobras varia entre $0,5 \% 0$ e $30 \% 0$ e a das salinas é igual ou superior a 30\%0. Neste texto, serão objeto de análise apenas as águas doces.

Um ponto a destacar é que a classificação se refere às águas genericamente, e não a corpos hídricos específicos. Apenas cuida-se de fixar níveis de qualidade em tese e, a partir dessa fixação, estabelecer os usos com eles compativeis.

As águas doces se classificam, segundo seus usos preponderantes, sempre em função da qualidade estabelecida, nos termos do art. $1^{9}$ da Resolução em análise, em:

"I - Classe Especial - águas destinadas: a) ao abastecimento doméstico sem prévia ou com simples desinfecção; b) à preservação do equilíbrio natural das comunidades aquáticas.

II - Classe 1 - águas destinadas: a) ao abastecimento doméstico após tratamento simplificado; b) à proteção das comunidades aquáticas; c) à recreação de contato primário (natação, esqui aquático e 
mergulho); d) à irrigação de hortaliças que são consumidas cruas e de frutas que se desenvolvam rentes ao solo e que sejam ingeridas cruas sem remoção de película; e) à criação natural e/ou intensiva (aquicultura) de espécies destinadas à alimentação humana.

III - Classe 2 - águas destinadas: a) ao abastecimento doméstico, após tratamento convencional; b) à proteção das comunidades aquáticas; c) à recreação de contato primário (esqui aquático, natação e mergulho); d) à irrigação de hortaliças e plantas frutíferas; e) à criação natural e/ou intensiva (aquicultura) de espécies destinadas à alimentação humana.

IV - Classe 3 - águas destinadas: a) ao abastecimento doméstico, após tratamento convencional; b) à irrigação de culturas arbóreas, cerealíferas e forrageiras; c) à dessedentação de animais.

V - Classe 4 - águas destinadas: a) à navegação; b) à harmonia paisagística; c) aos usos menos exigentes".

Essa classificação possui um sentido de proteção, não da água propriamente, mas da saúde pública, pois é evidente a preocupação em segregar a água que pode ser utilizada para, por exemplo, irrigar hortaliças que se consomem cruas. Ou ainda a água que serve para abastecimento sem prévia desinfecção, sem, é claro, expor a população a riscos de contaminação por vetores hídricos. Nota-se ainda uma preocupação com o fator econômico, em relação aos custos de desinfecção da água para abastecimento público.

No que se refere às águas doces, fica evidente que a qualidade da água se relaciona estreitamente com os usos mais próximos ao homem. Nos "consideranda" do diploma legal em tela, verifica-se, dentre outras, a preocupação com:

a) defesa dos níveis de qualidade da água, avaliados por parâmetros $e$ indicadores específicos, com a finalidade de assegurar seus usos preponderantes;

b) possibilidade de melhor adequação dos custos do controle da poluição quando os níveis de qualidade exigidos estão de acordo com os usos que se pretende dar ao corpo d'água ou seus diferentes trechos;

c) a saúde e o bem-estar humano, bem como o equilíbrio ecológico aquático, que nis devem ser afetados como conseqüência da deterioração da qualidade das águas.

Viu-se que classificar é estabelecer níveis de qualidade para a água e fixar os usos compativeis com tais níveis. Em um segundo passo, por meio do instituto do enquadramento dos corpos hídricos, aplica-se, em corpos 
hídricos específicos, ou em trechos deles, as classes de água ou níveis de qualidade fixados, determinando-se os usos ou a finalidade preponderante de cada um deles. É o enquadramento dos corpos hídricos em classes de usos preponderantes.

O art. $2^{\circ}$ da Resolução CONAMA 20/86 conceitua, na alínea $b$, assim como a Resolução $\mathrm{CNRH}$, art. $1^{\circ}$, inciso I, o enquadramento como sendo "estabelecimento de nível de qualidade (classe) a ser alcançado e/ou mantido em um segmento de corpo de água ao longo do tempo". O enquadramento consiste em um dos instrumentos da Política Nacional de Recursos Hídricos, conforme dispõe a Lei n. 9.433/97, em seu art. 5², inciso II.

Nos "consideranda" da Resolução CONAMA 20/86, menciona-se que - enquadramento dos corpos d'água deve estar baseado não necessariamente em seu estado atual, mas nos níveis de qualidade que deveriam possuir para atender às necessidades da comunidade.

A importância do enquadramento refere-se, também, ao fato de ser o mesmo, indiretamente, um mecanismo de controle do uso e ocupação do solo localizado na bacia hidrográfica. De fato, se um trecho de rio tem o enquadramento de Classe 1, fica restrita a implantação de empreendimentos cujos usos sejam incompatíveis com aqueles indicados para essa categoria, como, por exemplo, a indústria que lança resíduos industriais em corpos hídricos, a menos que esteja dentro dos padrões estabelecidos para o lançamento, o que é discutido no processo administrativo de licenciamento ambiental da mesma.

Outra questão a colocar refere-se às competências: o município, por força da Constituição Federal, em seus arts. 30 , inciso VIII, e 182, é a pessoa jurídica de direito público interno que estabelece, mediante lei municipal, as condições de ocupação do solo. Os instrumentos que regulam a ocupação do solo são o plano diretor e a lei de zoneamento.

Nesse sentido, cabe lembrar que a Lei n. 9.433/97 estabelece, em seu art. 31, que na implementação da Política Nacional de Recursos Hídricos os Poderes Executivos do Distrito Federal e dos municípios promoverão a integração das políticas locais de saneamento básico, de uso, ocupação e conservação do solo e de meio ambiente com as políticas federal e estadual de recursos hídricos.

Nos termos do art. $9^{9}$, da Lei n. 9.433/97, é finalidade do enquadramento: "I. Assegurar às águas qualidade compatível com os usos mais exigentes a que forem destinadas. II. Diminuir os custos de combate à poluição das águas, mediante ações preventivas permanentes".

Como se pode notar, a norma jurídica sobre classificação e enquadramento consiste, em tese, em um mecanismo bastante eficiente, para 
ordenar o uso da água. O ponto cruciante sobre a classificação e o enquadramento dos rios é que o desrespeito às normas legais faz com que praticamente se desconheça a sistemática ora abordada, ignorando-se praticamente o enquadramento como fator de definição da qualidade da água de um corpo hídrico e, conseqüentemente, dos usos preponderantes a que 0 mesmo será submetido.

\section{CONCLUSÃO}

O ordenamento jurídico brasileiro é bastante claro, em suas várias normas, sobre a indissociabilidade dos temas concernentes à saúde e aos recursos hídricos. Tanto a Lei da Saúde, Lei n. 8.080/90, como a Lei de Águas, Lei n. 9.433/97, dispõem sobre essa correlação, além das interfaces com a Política Nacional do Meio Ambiente. As normas reguladoras também dão continuidade a essa estreita relação.

O direito brasileiro fornece as necessárias ferramentas para que a Administração Pública, na condução de suas finalidades, possa promover a convergência desses temas, que devem ser conjuntamente considerados, na tomada de decisões, seja sobre saúde, seja sobre o ambiente.

O Sistema Único de Saúde (SUS) e os Sistemas Nacional e Estaduais de Gerenciamento dos Recursos Hídricos possuem interfaces e meios legalmente estabelecidos para participar das decisões e atividades concernentes à proteção da água e à manutenção da saúde pública. 